\title{
ÉTUDES SUR LE POUSSIN
}

\author{
Recherches faites par C. CALET et J. BARATOU \\ Station de Recherches avicoles, \\ Centre national de Recherches zootechniques, fouy-en-Josas (Seine-et-Oise).
}

\section{MÉTHODE}

Nous avons montré (CAlET, Jouandet, Baratov, 1961) que l'efficacité protidique d'un aliment se manifeste au mieux lorsque l'animal reçoit une quantité limitée de la source azotée étudiée et lorsqu'il dispose en même temps d'un aliment non azoté ad libitum. On pouvait tirer de cette observation une méthode d'estimation de la qualité des matières premières destinées à l'alimentation du bétail et en particulier celles qui sont le plus appréciées pour couvrir les besoins azotés des animaux ${ }^{1}$. C'est pourquoi nous avons cherché à comparer notre technique et celle classiquement admise, décrite par les auteurs anglo-saxons sous les termes de "Gross Protein Value "et reprise récemment par RaND et al., 1960. Dans cette dernière méthode on constitue des régimes semi-synthétiques qui titrent $10 \%$ de protéine brute et qui sont distribués ad libitum. On établit le graphique de la croissance en fonction de la consommation d'aliment. Les résultats sont rapportés à ceux donnés par un lot sans azote. Dans le cas présent, nous avons modifié cette technique en limitant la quantité d'aliment $(23 \mathrm{~g}$ par jour et par poussin) de manière à comparer l'ensemble des résultats sur la base d'une ingestion égale de matières azotées ( $5 \mathrm{~g}$ par poussin et par jour).

Dans notre méthode, chaque animal reçoit un repas azoté qui lui fournit $5 \mathrm{~g}$ de protéine brute par jour. Il dispose en outre ad libitum d'un aliment non azoté. On enregistre la croissance des animaux, leur consommation d'aliment non azoté et l'on mesure la quantité d'azote retenu sous forme de tissu protidique.

Dans les deux méthodes les résultats sont comparés à ceux donnés par un lot recevant un protide de référence, en l'occurence l'albumine du blanc d'œuf cuit.

L'expérience est entreprise sur des poussins mâles âgés de 4 semaines et élevés en cage individuelle. Elle dure 11 jours.

Les matières azotées testées sont les farines de poisson ayant été préparées à trois températures différentes.

\section{RÉSULTATS ET DISCUSSION}

Les résultats figurent dans les tableaux 1 et 2 .

Nos résultats montrent que nous n'avons pas été en mesure de mettre en évidence les avantages de notre méthode par rapport à des méthodes plus anciennes. Il faut cependant remarquer dans le cas présent que les échantillons étaient particulièrement mal choisis, puisque aucune différence significative n'a pu être révélée entre les 3 farines quel que soit le critère de mesure employé.

Ainsi il apparaît que le mode de chauffage, - dans les limites où il a été étudié -, ne retentit pas sur la valeur alimentaire des farines de poisson. Il convient toutefois de

1. Les détails de la méthode sont fournis par CALET et MÉLOT, 1961. 
souligner que l'expérience a été effectuée peu de temps après la préparation des échantillons et par conséquent seuls les effets de la cuisson et du séchage pouvaient être observés et non pas les conséquences du stockage.

\section{Tableau 1}

Efficacité comparée de trois échantillons de farines de poisson mesurée par la méthode de Rand et al., 1960 modifiée.

\begin{tabular}{|c|c|c|}
\hline & $\begin{array}{l}\text { Gain de poids } \\
\text { en grammes par poussin }\end{array}$ & $\begin{array}{c}\text { Indice } \\
\text { de consommation }\end{array}$ \\
\hline Albumine $\ldots \ldots \ldots \ldots \ldots \ldots \ldots \ldots \ldots$ & 46,3 & 5,50 \\
\hline Poisson $60^{\circ} \ldots \ldots \ldots \ldots \ldots \ldots \ldots \ldots$ & 83,2 & 3,06 \\
\hline Poisson $90^{\circ} \ldots \ldots \ldots \ldots \ldots \ldots \ldots \ldots$ & 86,0 & 2,96 \\
\hline Poisson $130^{\circ} \ldots \ldots \ldots \ldots \ldots \ldots$ & 83,9 & 3,02 \\
\hline 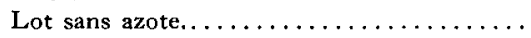 & $-45,2$ & - \\
\hline
\end{tabular}

TABleaU 2

Efficacité comparée de trois farines de poisson mesurée par la nouvelle méthode.

\begin{tabular}{|c|c|c|c|}
\hline & $\begin{array}{c}\text { Gain de poids } \\
\text { en } \\
\text { g/poussin }\end{array}$ & $\begin{array}{l}\text { Consommation } \\
\text { d'aliment } \\
\text { non azoté } \\
\text { (g) }\end{array}$ & $\begin{array}{c}\text { Valeur protidique } \\
\text { nette }\end{array}$ \\
\hline Albumine $\ldots \ldots \ldots \ldots \ldots \ldots \ldots \ldots$ & 118,0 & 337,3 & 52,02 \\
\hline Poisson $60^{\circ} \ldots \ldots \ldots \ldots \ldots \ldots \ldots$ & 144,9 & 339,5 & 55,95 \\
\hline Poisson $90^{\circ} \ldots \ldots \ldots \ldots \ldots \ldots \ldots \ldots$ & 142,9 & 346,4 & 55,74 \\
\hline Poisson $130^{\circ} \ldots \ldots \ldots \ldots \ldots \ldots \ldots$ & 137,8 & 340,9 & 55,25 \\
\hline Sans azote $\ldots \ldots \ldots \ldots \ldots \ldots \ldots$ & $-\quad 42,5$ & 238,0 & - \\
\hline
\end{tabular}

\section{RÉFERENCES BIBLIOGRAPHIQUES}

Calet C., Jouandet C., Baratou J., 1961. Variation de la consommation spontanée d'énergie du poussin en fonction de la nature des matière azotées du régime. Ann. Biol. anim. Biochim. Biophys., 1, 5-9.

Calet C., MÉlot M., 1961. Efficacité comparée pour la croissance du poussin de la méthionine et du sel de calcium de l'acide hydroxyméthylbutyrique (M. H. A.). Ann. Zootech. 10, 205-213.

Rand N. T., Collins V. K., Varner D. S., Mosser J. D., 1960. Biological evaluation of the factors affecting the protein quality of fish meals. Poult. Sci., 39, 45-53. 